\title{
China-2025: Research and Innovation Landscape
}

Epaminondas Christofilopoulos

Head of International Cooperation, PRAXI Network/ Foundation for Research and Technology Hellas; Co-Chair, Millennium Node Greece / Phemonoe Lab. Address: 1 Morihovou Sq., 54625 Thessaloniki, Greece. E-mail: christophilopoulos@gmail.com

\section{Stavros Mantzanakis}

CEO, EMETRIS SA; Head, Phemonoe Lab. Address: 9th Km. Thessaloniki - Thermi, THERMI Building A' Entrance, 60224 Thessaloniki, Greece. E-mail: stavros@phemonoe.eu

\begin{abstract}
$\mathrm{A}$ $s$ the second largest economy globally, China today is one of the drivers for changing the balance of forces worldwide. The country aims to become a global player on the high-tech product market, to make the transition from an investment-based to a knowledge-based economy, and become the largest consumer market that is attractive to other major international players, including the European Union. Aware of this trend, the European Commission initiated a foresight study to assess the future of science and innovation in China until 2025, the results of which we present in this paper.

The foresight study's objective was to identify Research and Innovation (R\&I) priority areas and their development by 2025 , aiming to contribute to the bilateral dialogue

between the EU and China with the ultimate goal developing of a long-term cooperation strategy.

Through a combination of desk-study analysis, a Delphi study, media scanning, crowd-sourcing platform, and a cross impact analysis, we analysed 16 critical drivers that play a substantial role in transforming China's R\&I landscape. The study showed a correlation between the different factors, and highlighted the strong impact of governance and the national economy on future developments. Taking into account these drivers and some critical uncertainties, we developed four plausible scenarios up to the year 2025. Being aware of these possible scenarios allows us to prepare in advance and establish a successful strategy for the future.
\end{abstract}

Keywords: China; science; research and development (R\&D); technology; innovation; trends; scenarios

DOI: $10.17323 / 1995-459 X .2016 .3 .7 .16$
Citation: Christofilopoulos E., Mantzanakis S. (2016) China 2025: Research \& Innovation Landscape. Foresight and STI Governance, vol. 10, no 3, pp. 7-16.

DOI: 10.17323/1995-459X.2016.3.7.16 


\section{Introduction: China on the brink of substantive changes}

Fifteen years ago, this report would have been written on American laptops, probably designed and engineered by IBM. However, the company that revolutionized the PC market sold its manufacturing division to Lenovo in 2004 [Vielmetter, Sell, 2014]. Instead, today we are typing using 'Made in China' computers, another signal of the rapid changes taking place globally and of China becoming a rising star. The post-war era has witnessed the economic miracles of Japan and South Korea, which managed to become substantial actors in the global high-technology market. However, both countries lacked the dynamism and size to transform the global economy and to control the rules of the game. Today, at the start of the $21^{\text {st }}$ century, two new countries, China and India (especially China) have the potential to shift the balance of global economy [Economist, 2014; Wolf et al., 2011].

Today China is the second largest economy after the United States and is expected to become the largest economy by 2050 [Hawksworth, Chan, 2013; Franklin, Andrews, 2012; Fan et al., 2014; Stephens, 2013; Hu, 2011]. In addition, China became the world's largest trading nation in 2013, overtaking the US in what Beijing described as 'a landmark milestone' for the country [Anderlini et al, 2014].

What is however more interesting, especially in China, is the on-going structural change of the national economy based on a shift from low-labour manufacturing to an increase in the service sector, internal consumption, and the production of high tech products [Fulin, 2013; Phemone Lab, 2013; Ansfield, 2012; Cyranosk, 2014]. This transformation of the Chinese economy is ongoing and it remain to be seen whether China will manage to become a global actor in added-value high tech products.

Will China lead or will it follow? During much of human history, China led the world in science and technology. However, recent Western stereotypes of a backward and unchanging China have negatively characterized the country.

Indeed, during and after the industrial revolution China lagged far behind. It is only in the last few decades that it has once again caught up. Today, change is happening rapidly and according to recent OECD data, today China is ahead of the EU for the first time in terms of the share of GDP spending on Research and Development [SPI et al., 2014]. Nonetheless, the picture is complex.

It is true that China has primarily excelled at adopting technologies from elsewhere, as a 'fast follower' [Global Times, 2013; Fu et al., 2013; Kostarelos, 2014; Springut et al., 2011]. However, in some fields it is on the frontier of technological knowledge, and the growth of published research is extraordinary. As for the commercialization of high tech innovative products, with its large growth and excess liquidity. China is eager to invest in new technologies to upgrade its production systems [Cyranosk, 2014; Casey, Koleski, 2011]. China (and other emerging markets) are now completing the innovation cycle by rapidly signing deals with innovative start-ups to quickly commercialize their new technologies at a rapid tempo and to scale.

Another important initiative, China's Foreign Experts Program, the 1000 talents program administered by the State Administration of Foreign Experts Affairs is expected to play a major role in transforming China into an innovative powerhouse in the future. The plan provides lucrative incentives to Chinese nationals who are living abroad to return to China to carry out research within their respective fields, especially in STEM disciplines. ${ }^{1}$

Nevertheless, several questions remain. Will Chinese research ever become a competitive world leader? Are financial growth, financial resources, and central planning sufficient to ensure growth? Are there any unforeseen risks? Some of these aspects will be covered by the current study.

\section{Methodology}

The overall work is structured around the following main research question: 'What are the main factors that will affect the Research (R) \& Innovation (I) Environment in China up to 2025?' The methodology is based on the TAIDA approach developed by KAIROS Future [Lindgren, 2013, Lindgren, Bandfold, 2003]. However, a tailor-made approach to this study also included several other research tools (e.g. crowd sourcing). We used a combination of a desk-study analysis, media scanning, a Delphi study, as well as a crowd-sourcing tool in different steps of the work to identify, define, and analyse 16 critical drivers that play a substantial role in transforming China's R\&I landscape, and construct four plausible scenarios of the future.

The overall work was structured as follows. The main task was to produce plausible scenarios about the Future of Research in China in 2025. Having that in mind, the trends scanning was limited to identifying the main factors that will shape the research environment in China during the next 15 years. The European Commission was the client of the study. Thus, the main interest is to provide scenarios and visualize some plausible futures to help make better strategic decisions today.

For our study, we developed a definition of the Inner World, the Near World, and the contextual Environment. The main actors of the system (internal and external) were identified and analysed by the project team.

\footnotetext{
For more information, see: http://www.1000plan.org/en/, accessed 19.02.2016.
} 
Then, we reviewed the historical development of the System (see step 2) affecting research in China to better understand current and future trends and identify unexpected developments.

We also identified a relatively large list of 'strong' trends affecting (directly or indirectly) research in China. We identified the trends through different tools: secondary research, media scanning, media watch, guruing (interviews with experts), and online questionnaires.

In addition, we also utilized a crowd sourcing platform (Co:tunity) throughout the study. ${ }^{2}$

Evaluation of the trends identified (in terms of importance and plausibility) happened through a minidelphi study, with input provided by a selected group of experts globally (China, Europe and elsewhere) through an online questionnaire. The 41 experts were evenly distributed across the world and had different backgrounds (research, business, consultancy, etc.). Yet, all shared considerable experience either on China or on Foresight methodology. We monitored the selected trends throughout the study (development pattern, saturation level, speeds, etc.)

We then analysed the driving forces behind the selected trends and their main consequences. In addition, tailor-made input on the current technological and innovation trends in China was provided by KAIROS Future [Lindgren, 2013]. This information was essential for identifying specific technological areas of high importance and for composing the final scenarios. Next, we carried out an in-depth analysis of the impact of the main selected trends on the Focal Question. Further, we analysed the influence of the different trends. The outcome of this analysis fed into the scenario-making process. The final report was validated by three independent experts, who provided comments and corrections on the suggested scenarios and trends.

\section{Trends analysis and evaluation}

After the initial analysis of the research environment and during the initial scoping phase, the project team agreed to focus on 16 drivers that will affect the quality and characteristics of the research environment in China by 2025. Some of these drivers are global in character but the majority are related to specific national developments.

It should be noted, however, that during this scanning process, the project team looked for drivers that will either obviously affect (or already have affected) the research environment. At the same time, the project team looked for weak signals to identify some less obvious factors that could potentially have a significant or even dramatic direct or indirect effect.

It should be also noted that some of the trends, studied in the context of this work, have a broader importance and affect the global system in varying ways. These megatrends (e.g. global communications) are long-term, transformational processes with global reach, broad scope, and a fundamental and dramatic impact. Table 1 shows the 16 selected trends.

The evaluation results of the 16 drivers are presented in the following graphs on a scale of one to ten in terms of their importance and their probability of occurring. Although most of the drivers got a high mark both in terms of their importance and probability (this is natural as we had pre-selected the important drivers), there were still several interesting results extracted by the evaluation process.

In terms of the importance of the drivers, we found the following to be most influential: the increasing need for energy and resource efficiency; structure and operation of the education system; environmental implications; framework conditions (the national regulatory framework for research); stability of the government and societal peace; and language skills (Figure 1).

Further, we analysed some of the aspects pertaining to trends evaluation. First, a very low importance rating was given to population growth and urbanization, despite their major impact on transforming society [Miller, 2012; Mingqi, 2013; Mai, 2013]. However, it seems that the serious indirect effects of these processes on research are far from obvious.

Second, very little importance was attributed to 'human rights' and the possibility of a serious military conflict in the region. The 'Economy' and 'Private R\&D investment' were also considered relatively unimportant possibly because the experts took them for granted.

Figure 2 schematically presents the probability ratings given by the experts (10 representing a higher probability). The highest probability is naturally attributed to ongoing distinct trends such as the rise of 'Global Communication', 'Connectivity', and 'Urbanization'. Moreover, it is broadly expected that issues like the 'Environment', 'Space and Defence', as well as 'Need for Resources' will continue to play an increasing role in the future. On the other hand, the experts had very low expectations for positive changes on issues like 'Human Rights', 'Governance', and the 'Education System' as well as on 'Intellectual Property Rights' (IPR). Finally, it is also important to underline that the risks are expected to affect both the Chinese and global economy.

Figure 3 summarizes the evaluation results of the trends, demonstrating the critical importance of 'Governance' and the 'National Economy' in shaping and catalyzing the research environment in

\footnotetext{
2 'Co:tunity' is a multi-functional smartphone and web application for collaborative trends potting and innovation developed by Kairos Future. Available at: www.cotunity.com, accessed 12.12.2015.
} 


\begin{tabular}{|l|l|}
\hline \multicolumn{1}{|c|}{ Object of the analysis } & \multicolumn{1}{c|}{ Predicted state } \\
\hline 1. Economy & China will enjoy strong GDP growth until 2025 \\
\hline 2. Framework Conditions & $\begin{array}{l}\text { The government will provide sufficient financial support and will implement an efficient regulatory } \\
\text { framework for research }\end{array}$ \\
\hline 3. Private R\&D investment & The private sector in China will invest more in R\&D by 2025 \\
\hline 4. Energy \& Materials & $\begin{array}{l}\text { The need for more energy from other sources beyond coal (e.g. from renewables and nuclear) and the } \\
\text { need for resources (e.g. alternative raw materials) will strongly increase in China by 2025 }\end{array}$ \\
\hline 5. Governance & China will enjoy stable governance and a peaceful society by 2025 \\
\hline 6. Urbanization & The urbanization process in China will continue until 2025 \\
\hline 7. Human Rights & In the years to come, China will see a greater openness and improvement of human rights \\
\hline 8. Global Economy & The global economy is expected to grow steadily until 2025 \\
\hline 9. Peace \& Conflict & Peaceful regional cooperation will support the growth of Chinese Research by 2025? \\
\hline 10. Space \& Defence & Space exploration efforts and the development of defence technologies will increase by 2025 \\
\hline 11. Environment & $\begin{array}{l}\text { The intensity of local environmental problems (e.g. atmospheric pollution, contaminated water) and } \\
\text { global environmental implications (e.g. climate change) will increase by 2025 }\end{array}$ \\
\hline 12. Population & The Chinese population will continue to increase by 2025 \\
\hline 13. IPR & $\begin{array}{l}\text { Intellectual Property Rights (IPR) regulations will be further modernized and IPR } \\
\text { enforcement will continuously improve in China by 2025 }\end{array}$ \\
\hline 14. Global Communication & $\begin{array}{l}\text { The world will become more interconnected and new communication technologies will allow stronger } \\
\text { global interactions and cooperation of Chinese researchers by 2025 }\end{array}$ \\
\hline 15. Language Skills & The language skills of Chinese researchers will substantially improve by 2025 \\
\hline 16. Education System & $\begin{array}{l}\text { The Chinese education system (primary/ secondary/ higher) will be radically modernized and upgraded } \\
\text { by 2025 }\end{array}$ \\
\hline Source: compiled by the authors. \\
\hline
\end{tabular}

China, followed by 'Energy \& Materials', 'R\&D Framework Conditions', the 'Education System', the 'Environmental Situation', and 'Language Skills'.

Tackling the need to prioritize trends, we carried out a Trend Impact Analysis (TIA) to identify the most important trends that will be central in formulating the scenarios. The following graph (Figure 4) summarizes the outcomes of the evaluation process, indicating the specific drivers that are of high importance and have a high probability of occurring.

The trends in the upper right corner were evaluated by the experts as certain and important. The trends in the top left corner were evaluated as uncertain (or less certain) but still highly important. These two sets of trends are, according to the scenario methodology, deemed of high importance and are studied in more detail as they play an important role in formulating the four scenarios.

The Cross-Impact Analysis (CIA) is an essential part of the scenario methodology that reveals how different trends affect each other and help analyse the interrelationships between them [Lindgren, Bandfold, 2003]. In the first step of the CIA analysis, we evaluated the influence of every factor or trend on the other factors, highlighting several important findings such as the strong role of the 'National

\section{Figure 1. Trends evaluation by importance}

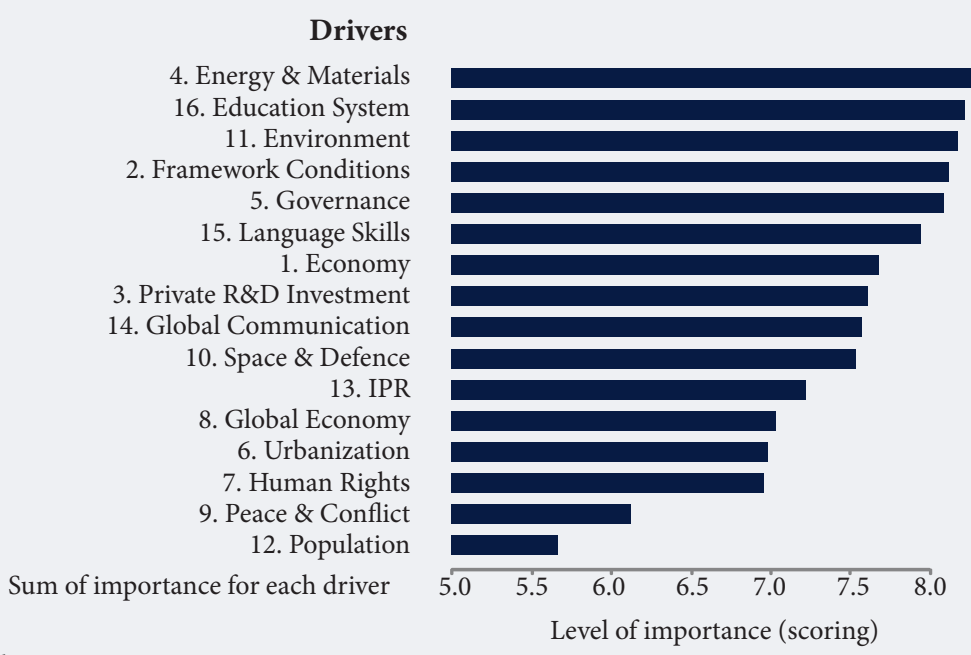

Source: compiled by the authors. 


\section{Figure 2. Trends Evaluation, Probability}

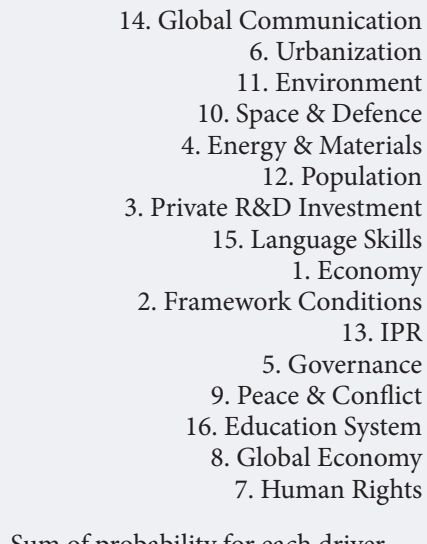

Sum of probability for each driver

Source: compiled by the authors.

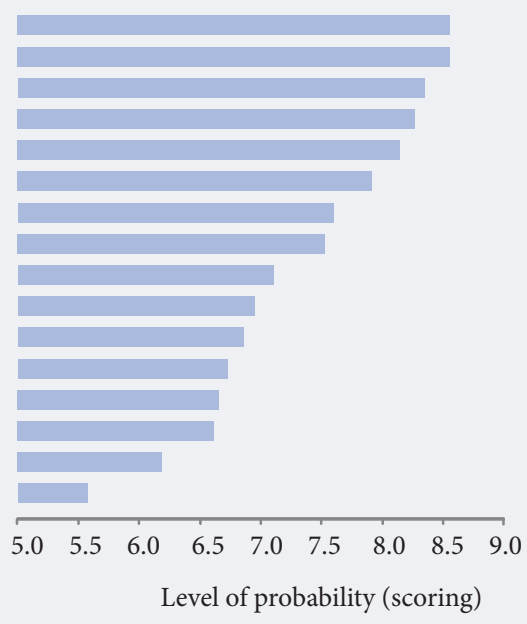

Level of probability (scoring)

Economy' and 'Private R\&D Investment' in transforming the R\&D environment, as well as the overall strong role of 'Governance.' The graphical visualization of the CIA (Figure 5) sheds light on several other issues such as the highly interdependent role of 'IPR'.

The main outcomes of the CIA analysis graphically presented above are as follows.

Governance is the major clear driving force and quite independent of other drivers. 'Urbanization', 'Global Communications' and 'R\&D Framework Conditions' are also important and quite independent driving forces.

The 'National Economy' is naturally a major driver as well and has the strongest interconnections with other drivers. 'Energy and Resources' is another important driver highly interconnected with several other factors such as the 'Economy' and 'Environment'.

'Private R\&D Investment' and 'IPR' are both highly dependent on other drivers. Several factors that have a strong effect on the R\&I environment in China up to 2025 are strongly dependent on 'Governance': 'Human Rights,' 'IPR' issues, 'Education', and 'Peace \& Conflict'.

'Environmental' issues, the 'Education' system, 'Language' Skills, 'Peace \& Conflict', and 'Human Rights' are strongly dependent on other factors ('Governance' in most cases).

\section{Figure 3. Trends in China ${ }^{\star}$}

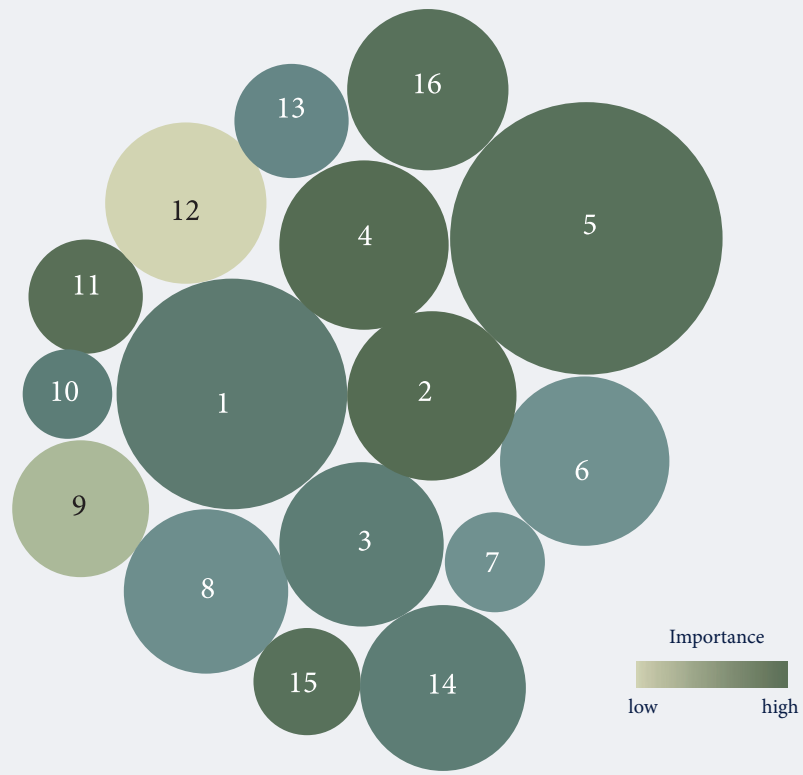

Source: compiled by the authors.
1. Economy

2. Framework Conditions

3. Private R\&D Investment

4. Energy \& Materials

5. Governance

6. Urbanization

7. Human Rights

8. Global Economy

9. Peace \& Conflict

10. Space \& Defence

11. Environment

12. Population

13. IPR

14. Global Communication

15. Language Skills

16. Education System

* Colour shows the sum of importance, while size shows the sum of influencing. 


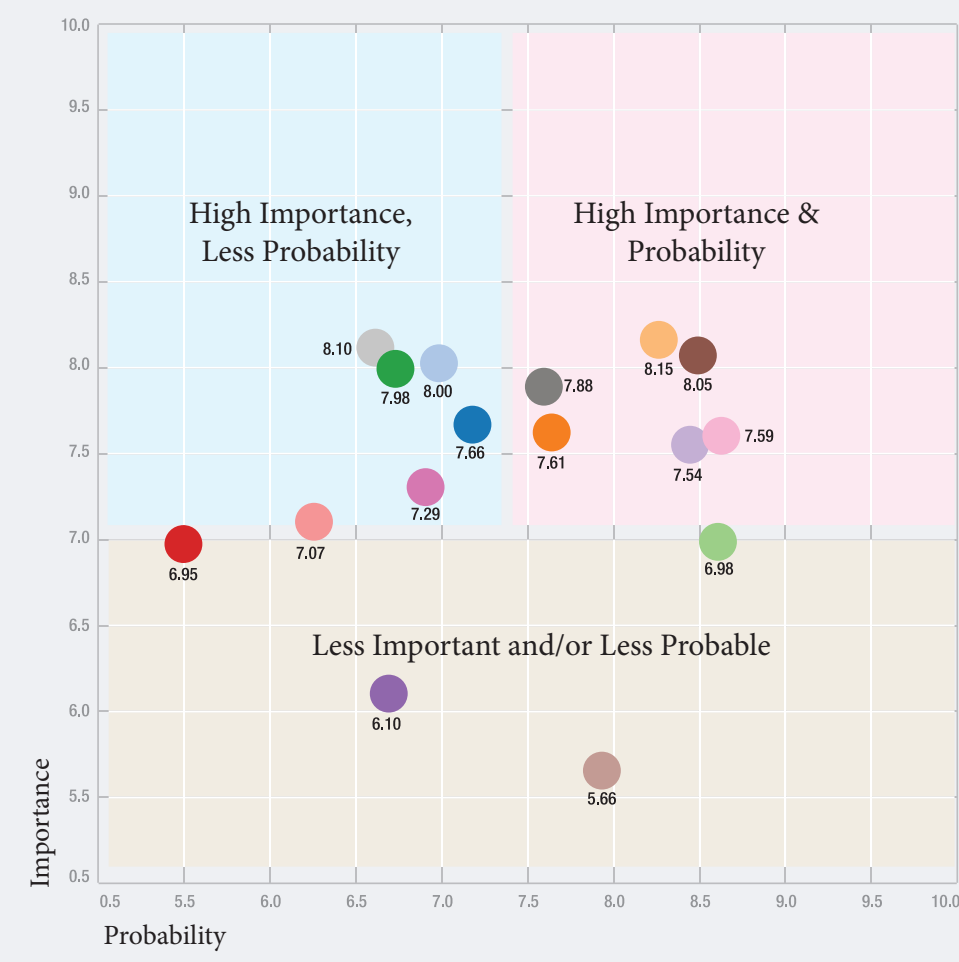

\section{Drivers}

1. Economy

2. Framework Conditions

3. Private $R \& D$ investment

4. Energy \& Materials

5. Governance

6. Urbanization

7. Human Rights

8. Global Economy

9. Peace \& Conflict

10. Space \& Defence

11. Environment

12. Population

13. IPR

14. Global Communication

15. Language Skills

16. Education System

Source: compiled by the authors.

Notes: The X axis represents the probability (ranking marks from 1 to 10 ), while the $\mathrm{Y}$ axis represents the importance of the same drivers on affecting the research environment (ranking marks from 1 to 10). Color shows details about driver.

The first phase of the study also included identifying wild cards. Wild cards are events that could cause a sudden and rapid radical change. These wild cards are very improbable because if they occur they will change the world as we know it. Such wild card events can substantially change the evolution of the future and should be taken into account during strategic planning [Mendonça et al., 2004; van Rij, 2013].

During the analysis, several wild cards appeared in the discussions of lesser or greater probability. Some of them are included in the developed scenarios. Some of the most likely wild card events that might radically affect China's research environment and the whole country are listed below:

- A brief military conflict in the South-East Chinese Sea could stop foreign investment, shift research funding and the focus on defence technologies, and stop bilateral cooperation;

- A nuclear accident could change the current government plans for several new nuclear plants in the near future;

- Massive 'domino effect' social unrest in the country fuelled by poor economic performance and poor civil rights could radically change the governance model in China;

- A collapse of the booming property market could cause a financial crisis and anger within the middle class.

This non-exhaustive list of wild cards is indicative of the various diverse unlikely incidents that may occur to suddenly alter the direction of the future. Some of the wild cards have been described in scenario narratives as they could dramatically change the linear development of the future trends.

\section{Key factors that impact the scenarios}

The trend scoping process was crucial not only to identify and study a large set of factors but also to initiate a discussion with a broader group of experts that provided feedback throughout the study.

After finalizing the trend analysis, we made some initial assumptions for the Future of Research in China at 2025 .

First, we assumed that strong state policy and investment will continue to guide research but will also limit it unless important framework changes occur [Sass, 2014; Orlik, 2013]. In the case of social unrest, research will also be affected. Moreover the state in areas such as Foreign Relations and the Space Race are expected to place some focus on defence/space related research.

Second, we assumed that the expected growth of the national and global economy will also benefit research. However, more financial risks are expected to slow down the development of the research environment. 


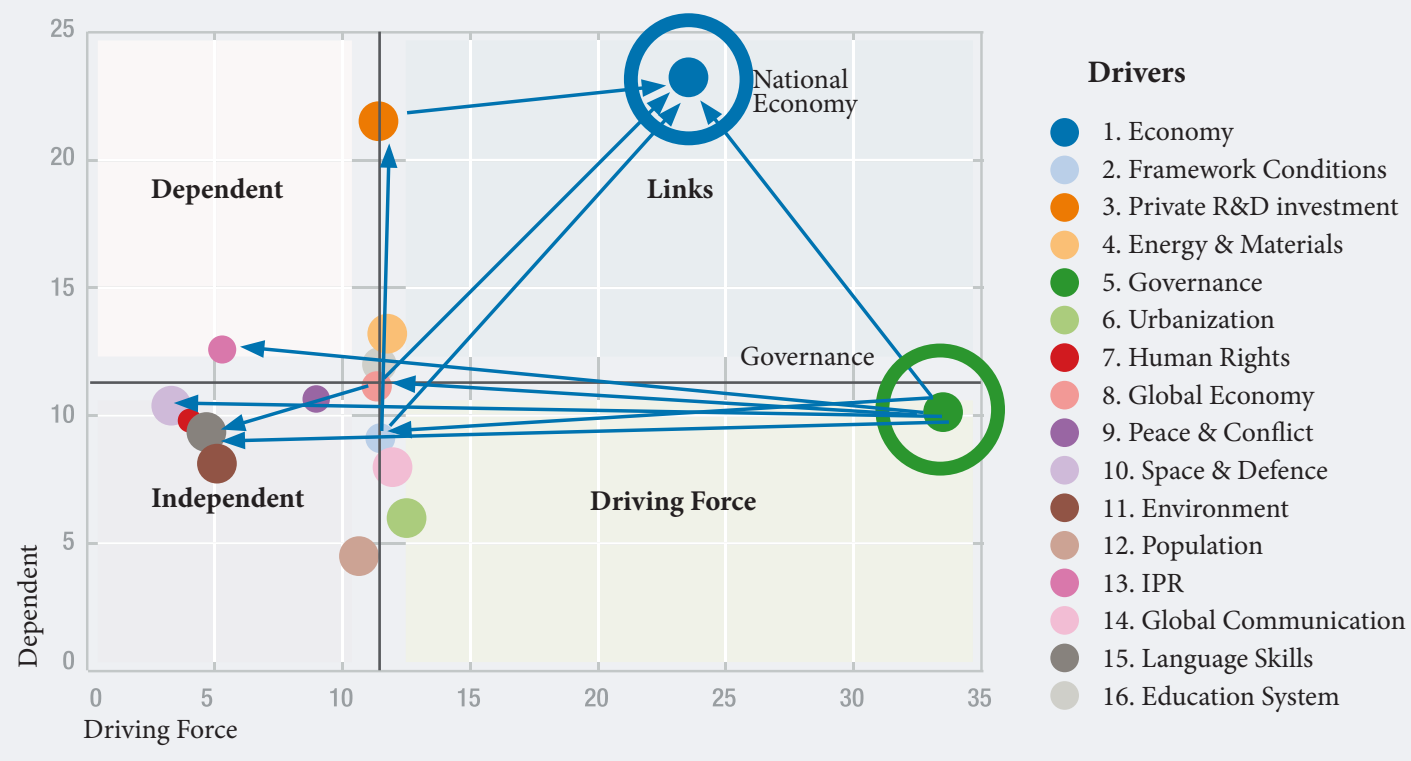

Source: compiled by the authors.

Third, we assumed that the quest for resources and environmental problems (local and global) will continue to be important drivers. We expect new technologies on alternative materials, next-generation nuclear plants, as well as on renewable energy to be developed.

Moreover, the Cross Impact Analysis and Causal Loop Analysis of the 16 identified trends showed that Governance and National Economy are the two key uncertain strategic trends affecting the development of the research environment. The research team ultimately selected these two strategic trends and used them as a basis for building the four scenarios.

\section{Governance and social peace}

Over the last few decades, the performance of the Chinese government has been widely considered successful given the country's impressive development [EIU, 2012; USPTO, 2014; Naisbitt, Naisbitt, 2010; Hu, 2011; Fan et al., 2014]. There is, however, great uncertainty about the future prospects for greater transparency, fair justice, and better protection of civil rights [NYT, 2014; World Bank, China State Council, 2013].

In recent years, there have been several cases of small-scale social uprisings in rural areas mainly due to pressure on ethnic minorities or corruption in local governance [NYT, 2013; Hoyos, 2014]. However, the main catalyst of change is expected to be the rising Chinese urban middle class.

In China, the relationship between the middle class and state corruption is underpinned by an implicit social contract based on prosperity and social stability. During the last few decades, the Chinese Communist Party (CCP) has supported, in the context of a broader urbanization process, the development of a middle class to drive consumption and serve as a buffer against other relatively deprived groups [Deng, 2012]. Nevertheless, at the same time middle class citizens participate more in 'rights-upholding' activities and are more likely to pursue legal action to resolve disputes. Given their superior resources too, including personal connections, internet access, and financial stability, the rising middle class is expected to become the catalyst of change in governing practices.

In the years to come, the Chinese governance system under the current president, Xi Jinping, will have to make decisions about greater transparency and justice or risk moving backwards towards a more despotic state [Zhang, 2012; Johnson, 2013] (Figure 6).

Each direction will dramatically affect the development of China's society, economy, and education, and thus will shape Chinese research in 2025.

\section{National Economy}

Both the global and national economy are considered important factors shaping research in China by 2025. However, the national economy was chosen as the second strategic trend upon which to build 


\section{Figure 6. Scenario axis 1 - Governance} and Societal Peace

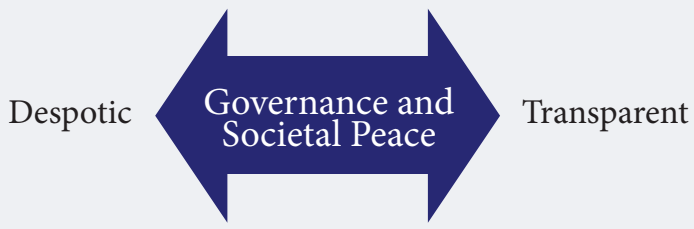

Source: compiled by the authors.
Figure 7. Scenario axis 2 - State of the National Economy

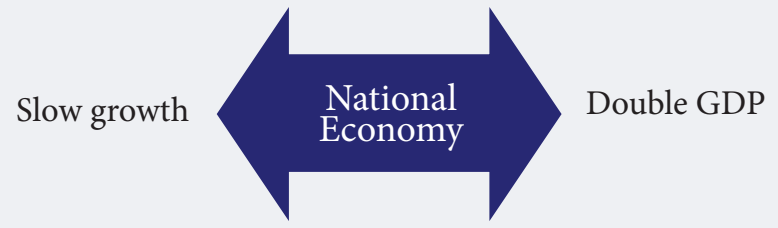

Source: compiled by the authors.

the scenarios because there are many ongoing structural changes in the national system, the success or failure of which will have dramatic effects upon the growth of the Chinese economy and research.

During the last few years, the Chinese economy has appeared to be quite durable, managing to deal successfully with the side effects of the global economic crisis.

The Chinese economy is undergoing a heavy transformation process to sustain growth and address the worsening environmental and social problems [NYT, 2014; Phemone Lab, 2013; Vltchek, 2012; Gong, 2012; Orlik, Davis, 2013]. The transformation includes the creation of a knowledge-based economy, moving from a 'made in China' to a 'designed in China' strategy, and from an investment-based to consumption-based economy. It also involves encouraging the creation of an urban middle-class, supporting the development of the services sector, facilitating changes in the banking system and interest rates, as well as changes in the ownership rights of agricultural land [Cyranosk, 2014; Fu et al., 2013; Global Times, 2013; Yang, 2013; Hansakul, 2013].

The General Secretary of the CCP's Central Committee, Hu Jintao, stated in his report to the $18^{\text {th }}$ National Congress of 2012 that by 2020, GDP income should be double that of 2010 on the basis of a more balanced, coordinated, and sustainable development path (meaning an annual GDP growth of 7.2\%) [Monan, 2012] (Figure 7).

By encouraging cleaner industries and the service sector, the government hopes to generate relatively more jobs, as well as clearer skies and waterways. However, this transition will require more bank loans, opportunities and policy support to SMEs, and less cheap loans to State Owned Enterprises (SOEs). It will also require innovative Chinese technologies to be created, successful urbanization, and unhindered cooperation with international business partners [Orlik, Davis, 2013; Sass, 2014; Global Times, 2013; Vltchek, 2012].

It should be also emphasized that the expected emergence of the Chinese consumer could be the greatest global growth engine of the $21^{\text {st }}$ century, benefiting European manufacturing and service enterprises alike.

\section{Scenarios: China 2025}

Based on the strategic uncertainties described above, we constructed four different scenarios for the future of Chinese research (Figure 8). The four scenarios are all set in 2025. For each, we give a short overview of the status and focal areas of Chinese research.

Yin \& Yang Scenarios - Under this scenario, the Chinese government under president Xi Jinping started substantial reforms in the transparency of governance and the judicial system in 2015, involving greater public participation in local governance. The economy is flourishing and is now based more on internal consumption, services, and high tech exports. Chinese research is a top global player, leading in terms of volume of public and private R\&D investment and producing two Nobel Prize winners in Chemistry and Medicine.

Blue Jasmine scenario - Here, the Chinese government under president Xi Jinping started substantial reforms in the transparency of governance and the judicial system in 2015, further enforced with the support of a dynamic urban middle class. Mr. Jinping has great popular support from the CCP and the public and was re-elected in 2018. However, the huge public debt of central and regional governments and the global 'Rare Earth Metals Crisis' of 2022 have stagnated the Chinese economy. Nevertheless, Chinese research is thriving driven by the substantial reforms in the national research system initiated in 2017 and by the many international research collaborations, especially in the fields of alternative materials, biotechnology, and health.

Dungeons \& Dragons scenario - Following these developments, the Chinese government under president, Xi Jinping, begun substantial reforms towards greater transparency and social balance in 2015. However, it proved impossible to overcome the hurdles set by a large group within the CCP and a new president was elected in 2018, leading the country in the opposite direction. The new authoritarian governance style 


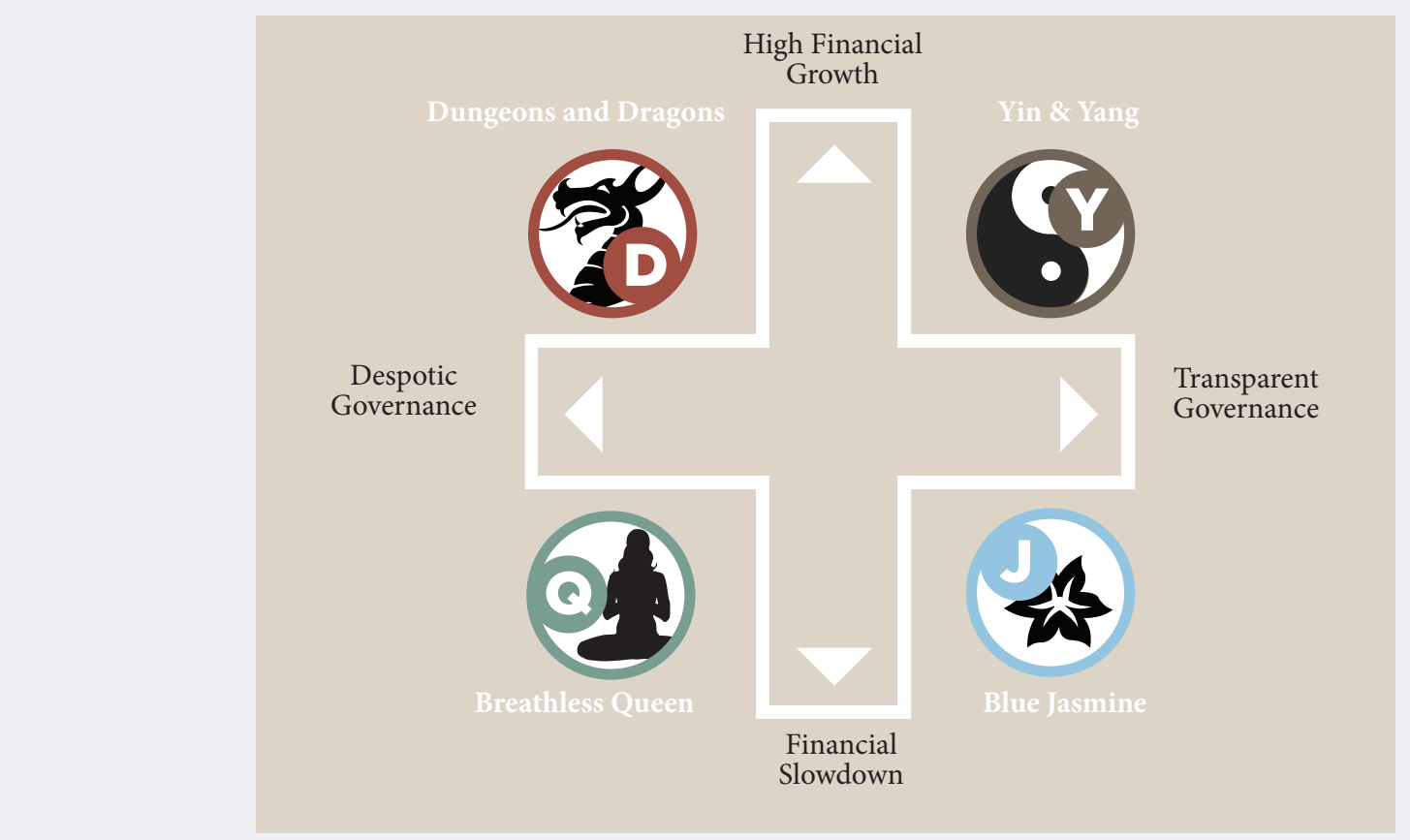

Source: compiled by the authors.

has managed to maintain high growth rates based not only on cost innovations but also on innovations in ICT, defence, space, and transport technologies.

The Breathless Queen scenario - This assumes that China is still a global power but with feet of clay, similar in many ways to the Soviet Union of the 1980s. The short-sighted and insufficient financial reforms have kept the growth rate below $3 \%$, fuelling several social side effects. Social unrest led by the middle class and ethnic minorities are creating an explosive mixture in Chinese society. The old-fashioned research system has limited funds and cannot keep up with advances in space, energy, and biotechnology.

\section{Conclusions}

Our study provided a general insight into the future of research and innovation activities in China up to 2025. With sufficient capacities in several scientific and technical areas, the country has sound prerequisites for improving its international status by shifting away from the 'world factory' image to becoming a global player in the market of innovative technologies with high-added value. It has excellent chances to move from an economy based on investment to one based on knowledge and become the largest consumer market that is attractive to other major international players, including the European Union. At the same time, reservations about social reforms aimed at improving, for example, human rights, the quality of education, as well as the country's possible participation in hostilities could hinder scientific and technological development.

Our analyses of the major trends likely to affect China's research and innovation, as well as the interrelationships between these trends, enable us to define the priorities of scientific and technological development of the country and identify their likely future development. We placed the two most influential factors - governance and the national economy - as matrices to develop four plausible scenarios of the innovative development of China by 2025. In drafting the scenarios, we took into account several wild cards - low-probability extreme events that could radically change the socioeconomic situation in the country and the selected strategic vector.

The four scenarios we produced help to reduce disbelief in all the likely futures for China and allow us consider that any of them are plausible and prepare strategies to achieve them. However, scenarios are not predictions; it is simply impossible to predict the future with certainty. Thus, we should consider them powerful tools that can help us today in perceiving the likely future and prepare a successful strategy to get there.

The study was performed by the Phemonoe Lab and PRAXI/FORTH in the context of the 'Dragon-Star' project funded by the European Commission. The authors would like to thank the independent experts who contributed to the study: Assistant Professor Anthony Howell, School of Economics at Peking University, Beijing, China; Mr Rikard Wallin, Managing Director at NCAB Group Sweden AB, Stockholm, Sweden; and Professor Daoliang Lee, China Agricultural University, Beijing, China. 


\section{References}

Anderlini J., Hornby L. (2014) China overtakes US as world's largest goods trader. Financial Time, 10.01.2014. Available at: http://www. ft.com/intl/cms/s/0/7c2dbd70-79a6-11e3-b381-00144feabdc0.html\#axzz3xQyvGRHu, accessed 15.02.2015.

Ansfield J. (2012) China's cyber police enlist foreign firms. International Herald Tribune, 15.11.2012.

Casey J., Koleski K. (2011) Backgrounder: China's 12th Five-Year Plan, Washington, D.C.: U.S. China Economic \& Security Review Commission.

Cyranosk D. (2014) Chinese science gets mass transformation. Nature, vol. 513, no 7519. Available at: http://www.nature.com/news/ chinese-science-gets-mass-transformation-1.15984, accessed 28.03.2015.

Deng Y. (2012) Amendments reflect CPC's resolve. China Daily, 15.11.2012.

Economist (2014) Asian worries about China's rise - The people concerned. Economist, 15.07.2014. Available at: http://www.economist. com/blogs/banyan/2014/07/asian-worries-about-china-s-rise? $\mathrm{fsrc}=\mathrm{scn} / \mathrm{fb} / \mathrm{wl} / \mathrm{bl} /$ thepeopleconcerned, accessed 23.04.2015.

EIU (2012) China's leadership handover: The changing of the guard, London, New York, Hong Kong, Geneva: Economist Intelligence Unit.

Fan C., Christmann-Budian S., Seus S. (2014) Research and Innovation Cooperation between the EU and China, Brussels, Karlsruhe: European Commission, Fraunhofer Institute for Systems and Innovation Research.

Franklin D., Andrews J. (2012) Megachange: The World in 2050, Hoboken, NJ: Wiley.

Fu J., Frietsch R., Tagscherer U. (2013) Publication activity in the Science Citation Index Expanded (SCIE) database in the context of Chinese science and technology policy from 1977 to 2012, Karlsruhe: Fraunhofer Institute for Systems and Innovation Research.

Fulin C. (2013) Blueprint and timetable for the future. China Daily, 28.02.2015.

Global Times (2013) Government call for growth driven by innovation. Global Times, 23.10.2013. Available at: http://www.globaltimes.cn/ content/817254.shtml, accessed 12.05.2014.

Gong P. (2012) Cultural history holds back Chinese research. Nature, vol. 481, no 7382, p. 411.

Hansakul S. (2013) Property market so far so good. China Daily, 28.02.2013.

Hawksworth J., Chan D. (2013) World in 2050 The BRICs and beyond: Prospects, challenges, and opportunities, London: PricewaterhouseCoopers LLP.

Hoyos C. (2014) Tensions in Asia help keep sales buoyant. Financial Times, 11.02.2014.

Hu A. (2011) China in 2020: A New Type of Superpower, Washington, D.C.: Brookings Institution Press.

Johnson C. (2013) China's Third Plenum: Go BiG or Go home?, Washington, D.C.: Centre for Strategic \& International Studies.

Kostarelos K. (2014) We face being buried under an avalanche of Chinese science. The Guardian, 24.01.2014.

Lindgren M. (2013) 21st Century Management: Leadership and Innovation in the Thought Economy, London: Palgrave Macmillan.

Lindgren M., Bandfold H. (2003) Scenario Planning: The Link between Future and Industry, London: Palgrave Macmillan.

Mai L. (2013) The urbanization solution. Global Times, 25.02.2013.

Mendonça S., Cunha M.P., Kaivo-oja J., Ruff F. (2004) Wild Cards, Weak Signals and Organisational Improvisation. Futures, vol. 36, no 2, pp. 201-218.

Miller T. (2012) China's Urban Billion: The Story behind the Biggest Migration in Human History (Asian Arguments), London: Zed Books.

Mingqi X. (2013) Social, financial woes loom for China's expanding cities. Global Times, 25.02.2013.

Monan Z. (2012) Turning point for growth. China Daily, 14.11.2012.

Naisbitt J., Naisbitt D. (2010) China's Megatrends: The 8 Pillars of a New Society, New York: Harper Business.

NYT (2013) Desperation in Tibet. New York Times, 02.12.2013. Available at: http://www.nytimes.com/2013/11/30/opinion/desperationin-tibet.html, accessed 15.08.2015.

NYT (2014) China Rethinks its judicial system. New York Times, 18.03.2014. Available at: http://www.nytimes.com/2014/03/18/opinion/ china-rethinks-its-judicial-system.html, accessed 15.08.2015.

Orlik T. (2013) China faces big budget for needed reforms. The Wall Street Journal Asia, 01.03.2013.

Orlik T., Davis B. (2013) Relief on China Growth Delivered with Caveats. The Wall Street Journal, 21.01.2013.

Phemonoe Lab (2013) China: Hungry for Energy. Phemonoe Lab, 23.12 2013. Available at: http://phemonoe.eu/el/china-hungry-energy/, accessed 12.06.2015.

Sass S.L. (2014) Can China innovate without dissent? New York Times, 22.01.2014. Available at: http://www.nytimes.com/2014/01/22/ opinion/can-china-innovate-without-dissent.html, accessed 15.08.2015.

Springut M., Schlaikjer St., Chen D. (2011) China's Program for Science and Technology Modernization: Implications for American Competitiveness, Arlington, VA: Centra Technology Inc.

Stephens P. (2013) China has thrown down a gauntlet to America. Financial Times, 29.11.2013.

SPI, UNU-MERIT, AIT (2014) STI China: Science Technology and Innovation Performance of China (D9: Final Report), Sociedade Portuguesa de Inovação, United Nations University - Maastricht Economic and Social Research Institute on Innovation and Technology, Austrian Institute of Technology GmbH.

USPTO (2014) Report on Patent Enforcement in China, Alexandria, VA: U.S. Patent and Trademark Office.

van Rij V. (2013) New Emerging Issues and Wild Cards as Future Shakers and Shapers. Recent Developments in Foresight Studies (eds. M. Giaoutzi, B. Sapio), New York: Springer Science \& Business Media, pp. 67-92.

Vielmetter Gr., Sell Y. (2014) Leadership 2030: The Six Megatrends You Need to Understand to Lead Your Company into the Future, New York: AMACOM.

Vltchek A. (2012) China dares to evolve differently. China Daily, 15.11.2012.

Wolf Ch., Dalal S., DaVanzo J., Larson E.V., Akhmedjonov A., Dogo H., Huang M., Montoya S. (2011) China and India, 2025: A Comparative Assessment, Pittsburgh: RAND Corporation.

World Bank, China State Council (2013) China 2030: Building a Modern, Harmonious, and Creative Society, Washington, D.C.: World Bank, Development Research Center of the State Council of the People's Republic of China. DOI: 10.1596/978-0-8213-9545-5.

Yang C. (2013) Price controls urged as property market soars. Global Times, 21.02.2013.

Zhang W. (2012) Meritocracy versus Democracy. International Herald Tribune, 11.11.2012. 